\title{
Objective age of acquisition for 223 Italian words: Norms and effects on picture naming speed
}

\author{
LORELLA LOTTO \\ University of Padua, Padua, Italy \\ AND \\ LuCa Surian ANd REMo Job \\ University of Trento, Trento, Italy
}

\begin{abstract}
The present study provides a set of objective age of acquisition (AoA) norms for 223 Italian words that may be useful for conducting cross-linguistic studies or experiments on Italian language processing. The data were collected by presenting children from the ages of 2 to 11 with a normed picture set (Lotto, Dell'Acqua, \& Job, 2001). Following the study of Morrison, Chappell, and Ellis (1997), we report two measures of objective AoA. Both measures strongly correlated with each other, and they also showed a good correlation with the rated AoA provided by adult participants. Furthermore, we assessed the relationship between the AoA measures and other variables used in psycholinguistic experiments. Regression analyses showed that familiarity, typicality, and word frequency were significant predictors of AoA. AoA, but not word frequency, was found to determine naming latencies. Finally, we present a path model in which AoA is a mediator in predicting speed in picture naming. The norms and the picture set can also be downloaded from http://dpss.psy.unipd.it/files/strumenti.php and from http://brm.psychonomic-journals.org/content/supplemental.
\end{abstract}

The past 30 years have seen a growing interest in the factors affecting the speed of processing in picture naming tasks. On this issue, normative data for different sets of line drawings have been provided for American English (Snodgrass \& Yuditsky, 1996), Welsh (Barry, Morrison, \& Ellis, 1997), British English (Ellis \& Morrison, 1998), Spanish (Cuetos, Ellis, \& Alvarez, 1999), Italian (Dell'Acqua, Lotto, \& Job, 2000; Székely et al., 2003), Icelandic (Pind, Jónsdóttir, Tryggvadóttir, \& Jónsson, 2000), French (Bonin, Peereman, Malardier, Méot, \& Chalard, 2003; Chalard, Bonin, Méot, Boyer, \& Fayol, 2003), Dutch (Martein, 1995; Severens, Van Lommel, Ratinckx, \& Hartsuiker, 2005), Japanese (Nishimoto, Miyawaki, Ueda, Une, \& Takahashi, 2005), and Canadian French (Sirois, Kremin, $\&$ Cohen, 2006). These studies are of particular importance for the experimenters, because they represent an indispensable tool to prepare experimental materials matched on critical psycholinguistic variables. Several variables concerning the words to be retrieved (e.g., length, frequency, imageability, familiarity, age of acquisition [AoA]) and the picture stimuli (e.g., name agreement, visual complexity) have been identified as affecting naming latencies. As was pointed out by Stadthagen-Gonzalez and Davis (2006), some of these variables - for example, word length - can be easily determined by the experimenter, whereas other variables, such as AoA and word frequency, depend on complex procedural decisions concerning algorithms and the corpus of data in which they are computed. For exam- ple, AoA can be computed relying on either adult speakers' subjective ratings or children's performance on naming tasks (e.g., Morrison, Chappell, \& Ellis, 1997).

A crucial and controversial point concerns the relative importance of different psycholinguistic variables. Past discussions among psycholinguistic researchers cited word frequency as the most important factor to predict picture naming latencies (e.g., Forster \& Chambers, 1973; Jescheniak \& Levelt, 1994). However, serious doubts on this conclusion have arisen recently because of the strong correlation between word frequency and AoA. Some studies have found that AoA, but not frequency, affected picture naming (e.g., Morrison, Ellis, \& Quinlan, 1992). More recent studies have shown independent contributions of both variables (e.g., Alario et al., 2004) and have reported that when AoA is controlled for, the contribution of word frequency to naming speed vanishes (Barry, Hirsh, Johnston, \& Williams, 2001; Bonin, Chalard, Méot, \& Fayol, 2002; Dell'Acqua et al., 2000; Kremin et al., 2001).

In light of these considerations, AoA deserves to be considered carefully for its theoretical and methodological implications. The main point concerns the validity of estimated AoA. In most normative databases, AoA is derived from estimates generated by adults, asking them when they think they first acquired a word in their native language. On the other hand, some databases provide objective AoA (see, e.g., Cannard \& Kandel, 2008; Piñeiro \& Manzano, 2000). At present, only a few stud-

L. Lotto, lorella.lotto@unipd.it 
ies have compared the rated AoA that was provided by adult responses and the objective AoA that was derived from children's responses on picture naming tasks (Álvarez \& Cuetos, 2007; Barbarotto, Laiacona, \& Capitani, 2005; Chalard et al., 2003; Morrison et al., 1997; Pind et al., 2000). These studies have shown a high correlation between the values obtained in the two procedures, suggesting that rated AoA is a valid measure of the age of acquisition. However, they also suggest that objective AoA, rather than adults' estimates, should be used when available (Ellis \& Morrison, 1998).

The purpose of the present article was threefold. First, our aim was to provide objective measures of AoA for a large set of Italian words. These norms are useful for preparing experiments in which children are involved as participants. And, since we used the same set of pictures that were tested in a previous study with adults (Dell'Acqua et al., 2000; Lotto, Dell'Acqua, \& Job, 2001), a number of comparisons between children and adults were potentially accessible (for comparisons between children and adults, see also D'Amico, Devescovi, \& Bates, 2001). AoA norms for a set of Italian words are already available for children between the ages of 3 and 6 years (Barbarotto et al., 2005). These norms were collected by presenting 80 color photographs from a memory test (see Laiacona, Barbarotto, Trivelli, \& Capitani, 1993, for details). In the present study, we considered a broader age range, including children from the ages of 2 to 11 , and we used a larger set of items $(N=$ 223) to provide a more comprehensive set of normative data for designing experiments involving Italian words.

Second, we compared objective and rated AoA measures in order to address a number of issues that have been raised by previous studies on AoA. For example, in Morrison et al.'s (1997) study, the correlation between the two measures was about .75 , and a similar correlation (i.e., .72) was found in the Icelandic version of Morrison et al.'s study (Pind et al., 2000). In a study on Italian, Barbarotto et al. (2005) found that their objective indices were more correlated with the objective data provided by Morrison et al. (1997) on English-speaking children than with the ratings estimated by Italian speaking adults in the Nisi, Longoni, and Snodgrass (2000) study (.77 vs. .63, respectively). Thus, a second aim was to assess the correlation between objective and rated AoA, and to evaluate whether rated AoA is a valid measure of objective AoA, given that, for the experimenters, it is clearly easier to collect data that are provided by adults rather than by children.

Third, we aimed to assess the relationship between AoA and other relevant psycholinguistic variables. In the present study, we controlled for word length and frequency, as well as for concept familiarity and concept typicality within its category. Finally, we also controlled for picture naming speed. In particular, our aim was to evaluate the main determinants of AoA and naming speed. We used structural equation models to show how AoA affects the picture naming speed of processing. In fact, most studies in this area are correlational, and others have investigated the relationship between a number of linguistic variables and naming latencies using multiple regression analyses. Structural equation models consider the model as a system of linear structural equations and estimate all of the structural coefficients directly rather than estimating each equation separately. Thus, with respect to the correlation analysis, the model examines the causal relationship among the variables, whereas with respect to the regression analysis, the model explores the relationships among the variables. In the present study, we assessed a model in which AoA is a crucial mediator in predicting picture naming speed.

To sum up, in the present study, we presented the objective AoA values for a set of 223 Italian words that were derived from a picture naming task. Following closely the criteria outlined by Morrison et al. (1997), the norms were collected by presenting children from the ages of 2 to 11 years with the picture set that was described in Lotto et al. (2001). Also, we compared the objective AoA obtained in the present study with the rated AoA provided by Italian adults and investigated the relationship between the AoA measures and other variables that are commonly considered in psycholinguistic experiments.

\section{METHOD}

\section{Participants}

The data were collected from 300 Italian children (for a summary of information, see Table 1). Their ages ranged from 2:0 (years:months) (in order to maximize the possibility to tap very early name productions), to $10: 11$, the highest age level that was tested by Morrison et al. (1997).

Children from the ages of 2:0 to 6:11 were split in 6-month age bands, and older children were split in 12-month age bands. Thirty children were tested in each of the two youngest age groups (2:0-2:5; $2: 6-2: 11$ ), and 20 children were tested in each of the remaining 12 groups. Participants lived in suburban areas of northern Italy; their native language was Italian, and some of them also spoke the local dialect. The social background was heterogeneous, with most children being from the middle class.

\section{Stimuli and Procedure}

All of the children who were older than 3 were presented with a set of 223 drawings from the DPSS set (Lotto et al., 2001). The set of pictures and norms are available on the Web site http://dpss .psy.unipd.it/files/strumenti.php. Younger children (2:0-2:11 years) were presented with a smaller set $(N=77)$. The reduced set included only those items that were named correctly by at least $40 \%$ of children in the next age band (3:0-3:5 years), on the assumption that none of the other, more difficult, items would be assigned an AoA below 3 ,

Table 1

Children Tested for the Objective AoA Norms in Each Age Band

\begin{tabular}{ccrr} 
& & \multicolumn{2}{c}{ Sex } \\
\cline { 3 - 4 } Age Bands & Mean Age & M & F \\
\hline $2: 0-2: 5$ & $2: 3$ & 15 & 15 \\
$2: 6-2: 11$ & $2: 9$ & 15 & 15 \\
$3: 0-3: 5$ & $3: 3$ & 10 & 10 \\
$3: 6-3: 11$ & $3: 8$ & 7 & 13 \\
$4: 0-4: 5$ & $4: 2$ & 12 & 8 \\
$4: 6-4: 11$ & $4: 8$ & 8 & 12 \\
$5: 0-5: 5$ & $5: 3$ & 6 & 14 \\
$5: 6-5: 11$ & $5: 8$ & 15 & 5 \\
$6: 0-6: 5$ & $6: 3$ & 13 & 7 \\
$6: 6-6: 11$ & $6: 9$ & 9 & 11 \\
$7: 0-7: 11$ & $7: 4$ & 9 & 11 \\
$8: 0-8: 11$ & $8: 4$ & 9 & 11 \\
$9: 0-9: 11$ & $9: 5$ & 9 & 11 \\
$10: 0-10: 11$ & $10: 5$ & 10 & 10 \\
\hline
\end{tabular}


following the criteria described below (see the Results section). In the complete set of pictures, there were 78 drawings of living objects and 145 drawings of artifacts. These broad categories were further divided into more specific ones (see Table 2).

Children were tested individually in a room in their school. They were told that the experimenter was going to show them many pictures of things, and they were asked to help her to remember their names. The 223 items were first arranged in one random order; then, the list was divided into four blocks of roughly equal size. To minimize order effects, the fours blocks were arranged in four different orders, following a balanced Latin square design, and each order was given to an equal number of participants in each age band. Each child was tested in two different sessions, which were held over 2 successive days.

\section{Scoring Procedure}

Two scores were computed for each picture, one on name agreement and the other on concept agreement. Name agreement was defined as the percentage of times that children produced the term most frequently used by adults, as was reported in Dell'Acqua et al.'s (2000) study. Concept agreement was defined as the percentage of valid responses referring to the same concept (e.g., cat and kitty), including synonyms of the most frequent names, diminutives, common abbreviations, or dialectal words. This measure represented how often a given picture was named correctly, regardless of the variability of the words used to name it. It is not to be confounded with the number of alternative names - a measure of how many different words are used to name a given picture, including the target name (Bates et al., 2003). If children corrected themselves immediately after producing a first incorrect word, their responses were considered appropriate. Small phonological deviations from the correct pronunciation were scored correct. Responses were recorded in writing by the experimenter.

\section{RESULTS}

\section{Criteria for Determining Objective AoA}

The objective AoA for each item was determined using two methods that were previously adopted by Morrison et al. (1997). The first method was based on curve-fitting logistic regressions using dichotomous values: Score 1 was assigned to correct responses, and Score 0 to incorrect responses. Logistic regressions estimate a curve for the children's naming behavior, and the curve is used to infer at which age a certain proportion of participants will name an item correctly. Separate curves were estimated for each item by using data from all participants and by entering participants' ages in months. Using the calculated curves, the age corresponding to the probability value of $50 \%$ was chosen as the objective AoA. Using this procedure, most items were assigned an AoA value between 12 and 131 months. However, some items were too easy (because they were learned before the lower boundary age interval we

Table 2

Semantic Categories in the Picture Set

\begin{tabular}{|c|c|c|c|}
\hline Artifacts & No. of Items & Living Beings & No. of Items \\
\hline Buildings & 16 & Fruit & 20 \\
\hline Clothes & 21 & Vegetables & 15 \\
\hline Containers & 6 & Mammals & 21 \\
\hline Furniture & 11 & Birds & 22 \\
\hline Musical instruments & 14 & & \\
\hline Tools & 25 & & \\
\hline Vehicles & 25 & & \\
\hline Weapons & 15 & & \\
\hline Mixed set & 12 & & \\
\hline Total & 145 & Total & 78 \\
\hline
\end{tabular}

selected), and others were too difficult (because they were learned after the upper boundary age interval). Twentyfive items did not enter the logistic curve-fitting function. The resulting AoA values are shown in the first column of Appendix A in the supplemental materials.

Following Morrison et al. (1997), we also employed the $75 \%$ rule as an alternative criterion. This second criterion was based on an arbitrary cutoff point of $75 \%$ correct responses. According to the $75 \%$ rule, the AoA assigned to an item should be the median value of the youngest agelevel group that reaches such percentage of success. This was followed by two subsequent age-level groups showing an equal, or better, performance. A total of 52 items failed to satisfy the $75 \%$ rule. Among these, 34 were difficult items that were also failed by adults, and no objective AoA value was assigned to them. To the remaining 18 items, we assigned an arbitrary AoA value of 140 months: Like Morrison et al., we assumed that the $75 \%$ criterion would have not been reached by the age group immediately subsequent to the oldest age band (10:0 to 10:1) that we actually tested. The resulting AoA values are shown in the second column of Appendix A.

An Excel-formatted version of the normative data is available online at http://dpss.psy.unipd.it/files/strumenti .php. The objective AoA values for the 223 words are reported in Appendix B, which provides the following information. In Columns 1 and 2, the correct pictures' names (in uppercase) and the alternative names, if any, (in lowercase) provided by children are reported in Italian and English, respectively. They are listed in the Italian alphabetical order. Columns 3 and 4 report, for each age band, the name agreement and the conceptual agreement scores for each picture, respectively.

In order to establish the relationship between the AoA and other variables used in psycholinguistic studies, we conducted both correlation and multiple regression analyses.

\section{Correlations Between AoA Measures and \\ Other Psycholinguistic Variables}

We investigated the correlations between the two AoA measures (AoA logistic regression [AoA-LR] and AoA 75\% [AoA-75] rule) and the various variables for which indexes were available from the Lotto et al. (2001) study. These included several adults' measures - namely, the rated AoA (on a 9-point scale), the latencies in naming the corresponding pictures (response times [RTs]), the typicality of the concepts represented in the pictures (following Rosch, Mervis, Gray, Johnson, \& Boyes-Braem [1976], ratings were collected on a 7-point scale), the concept familiarity (also rated on a 7-point scale), and the word frequency. Word frequencies were taken as in Lotto et al. (2001) by the Corpus of Contemporary Italian Language (Istituto di Linguistica Computazionale, 1988; for a more recent corpus of Italian language, see Bertinetto et al., 2005). The correlation analyses also included the child frequency of word usage reported by Marconi, Ott, Pesenti, Ratti, and Tavella (1994), who analyzed a corpus of about 500,000 words used in children's written essays, and the length of the words in letters. For each item, Appendix A lists the actual value for the variables we considered. 
Table 3

Correlation Matrix Among All the Independent Variables

\begin{tabular}{|c|c|c|c|c|c|c|c|c|}
\hline & AoA-75 & Rtd AoA & RTs & Typ & Fam & Ad. Frq. & Child Frq. & Length \\
\hline Objective AoA (LR) & $.958^{* * *}$ & $.752^{* * *}$ & $.503^{* * *}$ & $-.268^{* * *}$ & $-.289^{* * *}$ & $-.256^{* * *}$ & $-.246^{* * *}$ & .000 \\
\hline Objective AoA $(75 \%)$ & & $.698^{* * *}$ & $.495^{* * *}$ & $-.247^{* * *}$ & $-.275^{* * *}$ & $-.255^{* * *}$ & $-.232^{* * *}$ & .012 \\
\hline Rated (Rtd) AoA & & & $.313^{* * *}$ & $-.275^{* * *}$ & $-.401^{* * *}$ & $-.347^{* * *}$ & $-.295^{* * *}$ & .057 \\
\hline RTs picture naming & & & & $-.204^{* * *}$ & $-.163^{*}$ & $-.207^{* * *}$ & $-.183^{*}$ & .011 \\
\hline Typicality (Typ) & & & & & $.385^{* * *}$ & $.286^{* * *}$ & .161 & -.077 \\
\hline Familiarity (Fam) & & & & & & .133 & $.169^{*}$ & .043 \\
\hline Adult frequency (Ad. Frq.) & & & & & & & $.444^{* * *}$ & $-.261^{* * *}$ \\
\hline Child frequency (Child Frq.) & & & & & & & & -.143 \\
\hline
\end{tabular}

The results of the correlation analysis are reported in Table 3. Results show that words that are acquired earlier tend to be retrieved faster in picture naming tasks, are more typical, are more familiar, and are more frequent than words that are acquired later. AoA-LR and AoA-75 strongly correlated with each other (.958), and each of them correlated with all the other variables, with the exception of word length. Both AoA-LR and AoA-75 showed their highest correlation with rated AoA (.752 and .698 , respectively).

These results are very similar to those obtained by Morrison et al. (1997), Pind et al. (2000), and Chalard et al. (2003), in which the correlations between objective and rated AoA were .75, .72, and .74, respectively.

This finding confirms that the AoA rated by adults is a good estimate of objective word learning age. In fact, for all three measures of AoA, the pattern of correlations with the other variables is very similar. Each of the three measures of AoA correlated positively with RTs, and negatively with typicality, familiarity, and word frequency (both adult and child measures). However, a correlation of .752 between AoA-LR and rated AoA (.698 between AoA-75 and rated AoA) suggests that these variables are not equivalent. It is worth noticing that both objective measures showed their highest correlation with RTs (.503 and .495 for AoA-LR and AoA-75, respectively), whereas rated AoA showed its highest correlation with familiarity (.401). Typicality correlated in a very similar way with all three measures of AoA.

\section{Correlations Between Objective AoA Measures in Different Languages}

The correlations between the objective AoA values obtained in English (Morrison et al., 1997), French (Chalard et al., 2003), Spanish (Álvarez \& Cuetos, 2007), and Icelandic (Pind et al., 2000) are reported in Table 4. The

Table 4

Correlation Matrix Among Objective AoAs Reported for Italian, English (Morrison et al., 1997), French (Chalard et al., 2003), Spanish (Álvarez \& Cuetos, 2007), and Icelandic (Pind et al., 2000)

\begin{tabular}{|c|c|c|c|c|c|c|c|}
\hline Language & Italian-75 & English-LR & English-75 & French-LR & French-75 & Spanish-75 & Icelandic-75 \\
\hline \multicolumn{8}{|l|}{ Italian-LR } \\
\hline$r$ & .958 & .796 & .734 & .730 & .647 & .672 & .532 \\
\hline Significance & .000 & .000 & .000 & .000 & .000 & .000 & .000 \\
\hline No. of cases & 177 & 77 & 92 & 90 & 83 & 99 & 84 \\
\hline \multicolumn{8}{|l|}{ Italian-75 } \\
\hline$r$ & & .749 & .763 & .707 & .679 & .695 & .578 \\
\hline Significance & & .000 & .000 & .000 & .000 & .000 & .000 \\
\hline No. of cases & & 79 & 99 & 96 & 89 & 106 & 90 \\
\hline \multicolumn{8}{|l|}{ English-LR } \\
\hline$r$ & & & .970 & .771 & .653 & .626 & .549 \\
\hline Significance & & & .000 & .000 & .000 & .000 & .000 \\
\hline No. of cases & & & 80 & 68 & 64 & 71 & 64 \\
\hline \multicolumn{8}{|l|}{ English-75 } \\
\hline$r$ & & & & .793 & .695 & .645 & .580 \\
\hline Significance & & & & .000 & .000 & .000 & .000 \\
\hline No. of cases & & & & 87 & 83 & 91 & 83 \\
\hline \multicolumn{8}{|l|}{ French-LR } \\
\hline$r$ & & & & & .937 & .620 & .527 \\
\hline Significance & & & & & .000 & .000 & .000 \\
\hline No. of cases & & & & & 90 & 96 & 89 \\
\hline \multicolumn{8}{|l|}{ French-75 } \\
\hline$r$ & & & & & & .633 & .598 \\
\hline Significance & & & & & & .000 & .000 \\
\hline No. of cases & & & & & & 89 & 85 \\
\hline \multicolumn{8}{|l|}{ Spanish-75 } \\
\hline$r$ & & & & & & & 447 \\
\hline Significance & & & & & & & .000 \\
\hline No. of cases & & & & & & & 90 \\
\hline
\end{tabular}

Note-LR, logistic regression; $75,75 \%$ rule. 
Table 5

Multiple Regression Analysis on Age of Acquisition (Logistic Regression) As the Dependent Variable

\begin{tabular}{lccccc}
\hline \multicolumn{1}{c}{ Variable } & $\begin{array}{c}\text { Regression } \\
\text { Coefficient }\end{array}$ & $\begin{array}{c}\text { Standard } \\
\text { Error }\end{array}$ & $\begin{array}{c}\text { Beta } \\
\text { Coefficient }\end{array}$ & $t$ & $p$ \\
\hline Typicality & -2.36 & 1.41 & -0.13 & -1.97 & .046 \\
Familiarity & -3.97 & 1.42 & -0.21 & -2.79 & .006 \\
Adult frequency & -9.22 & 3.56 & -0.19 & -2.58 & .011 \\
\hline
\end{tabular}

Table 6

Multiple Regression Analysis on Age of Acquisition (75\% Rule) As the Dependent Variable

\begin{tabular}{lccccc}
\hline \multicolumn{1}{c}{ Variable } & $\begin{array}{c}\text { Regression } \\
\text { Coefficient }\end{array}$ & $\begin{array}{c}\text { Standard } \\
\text { Error }\end{array}$ & $\begin{array}{c}\text { Beta } \\
\text { Coefficient }\end{array}$ & $t$ & $p$ \\
\hline Typicality & -2.42 & 1.72 & -0.11 & -1.40 & .162 \\
Familiarity & -4.64 & 1.73 & -0.21 & -2.68 & .008 \\
Adult frequency & -11.50 & 4.35 & -0.19 & -2.64 & .009 \\
\hline
\end{tabular}

English and French studies used both the rule based on logistic regression and the $75 \%$ rule, whereas the Spanish and Icelandic studies used the $75 \%$ rule only. The results show that the correlations between the values obtained in the present study and those obtained in studies using other languages are very high and significant in all cases, in spite of the fact that there seems to be, prima facie, some differences among AoA values in the different studies. An analysis of this is behind the scope of the present article. However, it is tempting to say that the studies that cued children with the initial phoneme when they experienced difficulties in retrieving the name (Chalard et al., 2003; Morrison et al., 1997; Pind et al., 2000) reported lower AoA values than did the studies that did not cue children (Álvarez \& Cuetos, 2007, and our present study).

\section{Objective and Estimated AoAs}

Three separate regression analyses were carried out to examine the relationship between each of the three measures of AoA and some of the aforementioned variables. Specifically, typicality, familiarity, and adult word frequency were the independent variables tested as predictors of AoA-LR, AoA-75, and rated AoA.

As for AoA-LR, the overall equation for the multiple regression was significant $\left[R^{2}=.14 ; F(3,176)=9.80\right.$, $p<.0001]$. As can be seen in Table 5, AoA-LR is affected by typicality, familiarity, and word frequency.

As for AoA-75, the overall equation was significant $\left[R^{2}=.13 ; F(3,176)=8.90, p<.0001\right]$, and the measures of familiarity and word frequency resulted in reliable predictors of the AoA distribution (see Table 6).

As for rated AoA, the overall equation for the multiple regression was significant $\left[R^{2}=.25 ; F(3,176)=19.38\right.$, $p<.0001]$. As can be seen in Table 7, the AoA estimated by adults is affected by familiarity and word frequency.

The results of the regression analyses are in line with the results shown in previous investigations of AoA (see, e.g., Bird, Franklin, \& Howard, 2001; Gilhooly \& Logie, 1980; Morrison et al., 1997). For instance, Stadthagen-Gonzalez and Davis (2006) showed that all six variables included in the regression analysis made independent contributions to predicting AoA, with the best predictors being imageability and familiarity, followed by spoken and written frequency; the number of phonemes and neighborhood size showed lower $t$ values.

\section{AoA and RTs}

To determine which variables affect picture naming speed of processing, AoA-LR (i.e., the measure that best correlates with RTs) was entered, along with typicality, familiarity, and adult word frequency, in a multiple regression analysis. The overall equation was significant $\left[R^{2}=.26\right.$; $F(4,176)=15.32, p<.0001]$. As can be seen in Table 8, AoA-LR was the only significant predictor of RTs.

A similar pattern of results (with a lower $R^{2}$ ) was obtained when rated AoA was entered in place of AoA-LR $\left[R^{2}=.12 ; F(4,176)=5.85, p<.0001\right]$. In both analyses, frequency did not prove to be a significant predictor of picture naming speed of processing. As we said in the introduction, the relationship between frequency and AoA is still hotly debated, but the finding of the present research is in line with those of studies showing that when AoA is controlled for, the contribution of word frequency to naming speed vanishes (Barry et al., 2001; Bonin et al., 2002; Dell'Acqua et al., 2000; Kremin et al., 2001; Morrison et al., 1992). In a second regression analysis in which AoA was removed and frequency was entered together with typicality and familiarity, word frequency proved to be the only significant predictor of RTs; it is worth noticing that, in this case, the model had a much lower Nagelkerke $\left[R^{2}=.07 ; F(3,176)=4.57, p=.004\right]$. From these results, it can be argued that AoA and word frequency do not independently affect picture naming latencies. Interestingly, in a review of multitask investigations on the effect of AoA, Brysbaert and Ghyselinck (2006) found that the effect of AoA is markedly stronger than the effect of word frequency in picture naming, whereas in other tasks, such as word naming or lexical decision, the weights of the two measures are similar. Moreover, Barca, Burani,

Table 7

\begin{tabular}{lccccc}
\multicolumn{7}{c}{$\begin{array}{c}\text { Multiple Regression Analysis on Rated Age of } \\
\text { Acquisition As the Dependent Variable }\end{array}$} \\
\hline Variable & $\begin{array}{c}\text { Regression } \\
\text { Coefficient }\end{array}$ & $\begin{array}{c}\text { Standard } \\
\text { Error }\end{array}$ & $\begin{array}{c}\text { Beta } \\
\text { Coefficient }\end{array}$ & $t$ & $p$ \\
\hline Typicality & -0.61 & 0.71 & -0.63 & -0.85 & n.s. \\
Familiarity & -3.41 & 0.72 & -0.34 & -4.75 & .0001 \\
Adult frequency & -7.46 & 1.80 & -0.28 & -4.14 & .0001 \\
\hline
\end{tabular}

Table 8

Multiple Regression Analysis on Adults' RTs As the Dependent Variable

\begin{tabular}{lcccrc}
\hline \multicolumn{1}{c}{ Variable } & $\begin{array}{c}\text { Regression } \\
\text { Coefficient }\end{array}$ & $\begin{array}{c}\text { Standard } \\
\text { Error }\end{array}$ & $\begin{array}{c}\text { Beta } \\
\text { Coefficient }\end{array}$ & \multicolumn{1}{c}{$t$} & $p$ \\
\hline AoA-LR & 2.99 & 0.45 & 0.47 & 6.64 & .0001 \\
Typicality & -6.81 & 8.43 & -0.60 & -0.81 & n.s. \\
Familiarity & 0.56 & 8.59 & 0.01 & 0.06 & n.s. \\
Adult frequency & -21.73 & 21.50 & -0.07 & -1.01 & n.s. \\
\hline
\end{tabular}

Note-AoA-LR, age of acquisition-logistic regression. 


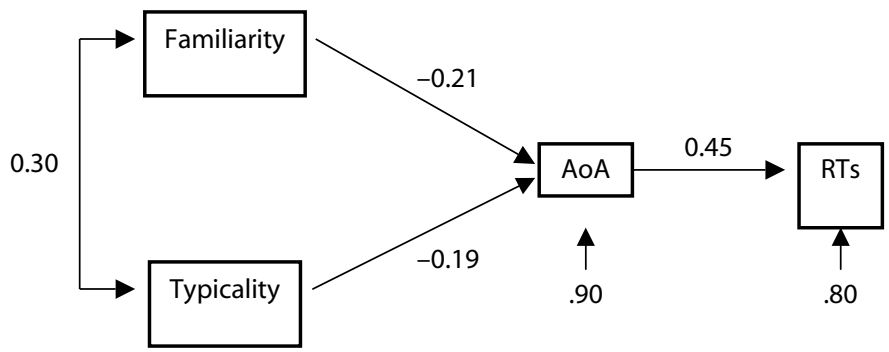

Figure 1. Standardized solution of Path Model 2. AoA, age of acquisition. RTs, response times.

and Arduino (2002) have shown that word frequency but not (rated) AoA affect latencies of word reading.

\section{Path Model}

To summarize the results obtained from both the correlation and multiple regression analyses, we propose a path model (see Figure 1) in which the relationships among familiarity, typicality, AoA-LR, and RTs are explored. The plausibility of the model has been verified by analyzing the correlation matrix of the four variables using the LISREL 8.7 method (Jöreskog \& Sörbom, 1996; Wright, 1934).

In the model, the independent variables were typicality and familiarity; the dependent variable was the RT; and the mediator variable was AoA-LR. In the saturated model, in which all the possible links are computed, the direct links between familiarity and RTs and between typicality and RTs were not significant.

Path Model 2 (in which we deleted the two nonsignificant links) is shown in Figure 1. The model assumes a direct relationship between typicality and familiarity, and a direct relationship between these two independent variables and AoA. By contrast, typicality and familiarity were postulated to predict RTs indirectly, through AoA mediation. The fit indices provided a good fit to the observed data $(\mathrm{NNFI}=1.05, \mathrm{CFI}=1.00, \mathrm{RMSEA}=$ $0.00)$, and the $\chi^{2}$ was not significant $\left[\chi^{2}(2 ; N=135)=\right.$ $1.09, p=.58]$ (Schermelleh-Engel, Moosbrugger, \& Müller, 2003). The $t$ values revealed that all of the causal relationships were significant. The model confirms that familiarity and typicality predict RTs with the mediation of AoA.

\section{DISCUSSION}

The main purpose of the present study was to present a normative set of objective AoA norms for 223 Italian words produced in a picture naming task by children from the ages of 2 to 11 . Following the criteria adopted by Morrison et al. (1997), we used two methods to compute word AoA. The first method (AoA-LR) was based on curvefitting logistic regression. Logistic regressions estimate a curve from children's naming responses, and the curve is used to infer at which age a certain proportion of participants will name an item correctly. The second method (AoA-75) was based on an arbitrary cutoff point of $75 \%$ correct responses. As was expected, as in Morrison et al.
(1997), we found a very high correlation between the values found in the two methods.

The second aim of the present work was to compare the two objective measures (i.e., AoA-LR and AoA-75) with the ratings estimated by Italian adults on the same pictures. The results of the correlation analysis showed a pattern very similar to that reported in Morrison et al.'s (1997) study, in the Icelandic version of Morrison et al.'s study (Pind et al., 2000), and in the French study (Chalard et al., 2003). Although a correlation of about .75 can be unquestionably considered a very good correlation, it also clearly shows that objective and rated AoAs are not equivalent. Therefore, although rated AoA is a valid and reliable alternative to the objective measure, we agree with Morrison et al. in recommending the use of the objective measures when available. On the other hand, the results of Barbarotto et al.'s (2005) study suggest a note of caution. Because they did not find a very high correlation between objective indexes of AoA and adult ratings, their results warn against the assumption that adult ratings are always valid alternatives for objective measures.

The third aim was to assess the relationship between AoA and some other variables used in psycholinguistic experiments. The results of the correlation analysis are in line with those of previous studies showing that earlyacquired words tend to be more familiar (e.g., Alario \& Ferrand, 1999; Barry et al., 1997; Pind et al., 2000), more typical (Dell'Acqua et al., 2000), more frequent (e.g., Alario \& Ferrand, 1999; Barry et al., 1997; Pind et al., 2000 ), and retrieved more quickly when naming pictures (e.g., Morrison \& Ellis, 2000; Morrison et al., 1992) than those that are acquired later.

The multiple regression analyses showed the composite nature of AoA: Familiarity, typicality, and word frequency were all significant predictors of this variable. As far as we know, typicality has been taken into consideration in only one previous normative study (Dell'Acqua et al., 2000), but, in light of its significant effect in the analysis using the LR criterion, it is our opinion that researchers should pay more attention to this variable, given the evidence that typicality plays a significant role in modulating picture naming latencies (e.g., Jolicœur, Gluck, \& Kosslyn, 1984). Furthermore, typicality is a relevant cognitive dimension when concepts must be categorized, and children acquire names for more typical items earlier than they do names for less typical items (Rosch, 1975). 
As far as naming speed is concerned, the regression analysis showed that once AoA was entered in the model, no other variable significantly increased the predictive power of the model. In line with previous studies (e.g., Chalard et al., 2003), the present study did not find an independent effect of word frequency on naming speed. This is consistent with the results of numerous studies reporting that when AoA was controlled for, the contribution of adult word frequency to naming speed vanished (Barry et al., 2001; Kremin et al., 2001). We found that word frequency was the main determinant of RTs only when we removed AoA in a second regression analysis. Taken together, these findings allowed us to propose a path model in which typicality and familiarity predict RTs indirectly, through AoA mediation.

In conclusion, the present study provided two useful measures of AoA for a large set of Italian words. The results showed a strong correlation between the two procedures used by Morrison et al. (1997), and a good correlation between the objective measures of AoA and those estimated by adults. Multiple regression analyses showed that objective AoA was sufficient by itself to predict the speed of picture naming, whereas word frequency was not a reliable independent determinant of RTs. The path analysis highlighted the crucial role of AoA as a mediator in predicting speed in picture naming.

\section{AUTHOR NOTE}

The present study was supported by a PRIN05 Grant from MIUR to R.J. Address correspondence to L. Lotto, Department of Developmental Psychology and Socialization, University of Padua, Via Venezia, Padua, Italy 35131 (e-mail: lorella.lotto@unipd.it).

\section{REFERENCES}

Alario, F.-X., \& Ferrand, L. (1999). A set of 400 pictures standardized for French: Norms for name agreement, image agreement, familiarity, visual complexity, image variability, and age of acquisition. Behavior Research Methods, Instruments, \& Computers, 31, 531-552.

Alario, F.-X., Ferrand, L., Laganaro, M., New, B., Frauenfelder, U. H., \& SEgUI, J. (2004). Predictors of picture naming speed. Behavior Research Methods, Instruments, \& Computers, 36, 140-155.

Álvarez, B., \& Cuetos, F. (2007). Objective age of acquisition norms for a set of 328 words in Spanish. Behavior Research Methods, 39, 377-383.

Barbarotto, R., Laiacona, M., \& Capitani, E. (2005). Objective versus estimated age of word acquisition: A study of 202 Italian children. Behavior Research Methods, 37, 644-650.

Barca, L., Burani, C., \& Arduino, L. S. (2002). Word naming times and psycholinguistic norms for Italian nouns. Behavior Research Methods, Instruments, \& Computers, 34, 424-434.

Barry, C., Hirsh, K. W., Johnston, R. A., \& Williams, C. L. (2001). Age of acquisition, word frequency, and the locus of repetition priming of picture naming. Journal of Memory \& Language, 44, 350-375.

Barry, C., Morrison, C. M., \& Ellis, A. W. (1997). Naming the Snodgrass and Vanderwart pictures: Effects of age of acquisition, frequency, and name agreement. Quarterly Journal of Experimental Psychology, 50A, 560-585.

Bates, E., D' Amico, S., Jacobsen, T., Székely, A., Andonova, E., DeVESCOVI, A., ET AL. (2003). Timed picture naming in seven languages. Psychonomic Bulletin \& Review, 10, 344-380.

Bertinetto, P. M., Burani, C., Laudanna, A., Marconi, L., Ratti, D., Rolando, C., \& Thornton, A. M. (2005). Corpus e Lessico di Frequenza dell'Italiano Scritto (CoLFIS) [Corpus and Frequency Lexicon of written Italian (CoLFIS)]. Available at www.istc .cnr.it/material/database/colfis/.
Bird, H., Franklin, S., \& Howard, D. (2001). Age of acquisition and imageability ratings for a large set of words, including verbs and function words. Behavior Research Methods, Instruments, \& Computers, 33, 73-79.

Bonin, P., Chalard, M., Méot, A., \& Fayol, M. (2002). The determinants of spoken and written picture naming latencies. British Journal of Psychology, 93, 89-114.

Bonin, P., Peereman, R., Malardier, N., Méot, A., \& Chalard, M. (2003). A new set of 299 pictures for psycholinguistic studies: French norms for name agreement, image agreement, conceptual familiarity, visual complexity, image variability, age of acquisition, and naming latencies. Behavior Research Methods, Instruments, \& Computers, 35, 158-167.

BRYSBAERT, M., \& GHYSELINCK, M. (2006). The effect of age of acquisition: Partly frequency related, partly frequency independent. Visual Cognition, 13, 992-1011.

CAnnard, C., \& Kandel, S. (2008). Impact of semantic or phonemic cues in picture-naming tasks on the calculation of the objective ageof-acquisition norms: A cross-linguistic study. Behavior Research Methods, 40, 1055-1064.

Chalard, M., Bonin, P., Méot, A., Boyer, B., \& Fayol, M. (2003). Objective age-of-acquisition (AoA) norms for a set of 230 object names in French: Relationships with psycholinguistic variables, the English data from Morrison et al. (1997), and naming latencies. European Journal of Cognitive Psychology, 15, 209-245.

Cuetos, F., Ellis, A. W., \& Alvarez, B. (1999). Naming times for the Snodgrass and Vanderwart pictures in Spanish. Behavior Research Methods, Instruments, \& Computers, 31, 650-658.

D'Amico, S., Devescovi, A., \& Bates, E. (2001). Picture naming and lexical access in Italian children and adults. Journal of Cognition \& Development, 2, 71-105.

Dell'AcQua, R., LotTo, L., \& Job, R. (2000). Naming times and standardized norms for the Italian PD/DPSS set of 266 pictures: Direct comparisons with American, English, French, and Spanish published databases. Behavior Research Methods, Instruments, \& Computers, 32, 588-615

Ellis, A. W., \& Morrison, C. M. (1998). Real age-of-acquisition effects in lexical retrieval. Journal of Experimental Psychology: Learning, Memory, \& Cognition, 24, 515-523.

Forster, K. I., \& Chambers, S. M. (1973). Lexical access and naming time. Journal of Verbal Learning \& Verbal Behavior, 12, 627-635.

Gilhooly, K. J., \& LogIe, R. H. (1980). Age-of-acquisition, imagery, concreteness, familiarity, and ambiguity measures for 1,944 words. Behavior Research Methods \& Instrumentation, 12, 395-427.

Istituto di Linguistica Computazionale (1988). Corpus di italiano contemporaneo. Unpublished manuscript.

JescheniaK, J. D., \& Levelt, W. J. M. (1994). Word frequency effects in speech production: Retrieval of syntactic information and of phonological form. Journal of Experimental Psychology: Learning, Memory, \& Cognition, 20, 824-843.

Jolicceur, P., Gluck, M. A., \& Kosslyn, S. M. (1984). Pictures and names: Making the connection. Cognitive Psychology, 16, 243-275.

JöRESKOG, K. G., \& SöRBOM, D. (1996). LISREL 8: User's reference guide. Chicago: Scientific Software International.

Kremin, H., Perrier, D., De Wilde, M., Dordain, M., Le Bayon, A., GatignOL, P., ET AL. (2001). Factors predicting success in picture naming in Alzheimer's disease and primary progressive aphasia. Brain \& Cognition, 46, 180-183

laiacona, M., Barbarotto, R., Trivelli, C., \& Capitani, E. (1993). Dissociazioni semantiche intercategoriali: Descrizione di una batteria standardizzata e dati normativi [Category specific semantic defects: A standardized test with normative data]. Archivio di Psicologia, Neurologia e Psichiatria, 54, 209-248.

Lotto, L., Dell'Acqua, R., \& Job, R. (2001). Le figure PD/DPSS. Misure di accordo sul nome, tipicità, familiarità, età di acquisizione e tempi di denominazione per 266 figure [The Psycholinguistic Database/Department of Psychology of Development and Socialization figures: Measurement of accord of name, type, familiarity, acquisition, and naming time for 266 figures]. Giornale Italiano di Psicologia, 28, 231-245.

Marconi, L., Ott, M., Pesenti, E., Ratti, D., \& Tavella, M. (1994). Lessico elementare: Dati statistici sull italiano scritto e letto dai bambini delle elementari. Bologna: Zarichelli. 
Martein, R. (1995). Norms for name and concept agreement, familiarity, visual complexity and image agreement on a set of 216 pictures. Psychologica Belgica, 35, 205-225.

Morrison, C. M., Chappell, T. D., \& Ellis, A. W. (1997). Age of acquisition norms for a large set of object names and their relation to adult estimates and other variables. Quarterly Journal of Experimental Psychology, 50A, 528-559.

Morrison, C. M., Ellis, A. W. (2000). Real age of acquisition effects in word naming and lexical decision. British Journal of Psychology, 91, 167-180.

Morrison, C. M., Ellis, A. W., \& Quinlan, P. T. (1992). Age of acquisition, not word frequency, affects object naming, not object recognition. Memory \& Cognition, 20, 705-714.

Nishimoto, T., Miyawaki, K., Ueda, T., Une, Y., \& TaKahashi, M. (2005). Japanese normative set of 359 pictures. Behavior Research Methods, 37, 398-416.

Nisi, M., Longoni, A. M., \& SNodgrass, J. G. (2000). Misure italiane per l'accordo sul nome, familiarità ed età di acquisizione per le 260 figure di Snodgrass e Vanderwart (1980) [Italian measurement on the relation of name, familiarity, and acquisition age for the 260 figures of Snodgrass and Vanderwart (1980)]. Giornale Italiano di Psicologia, 27, 205-218.

Pind, J., JónsdótTiR, H., TRYGgVadótTiR, H. B., \& Jónsson, F. (2000). Icelandic norms for the Snodgrass and Vanderwart (1980) pictures: Name and image agreement, familiarity, and age of acquisition. Scandinavian Journal of Psychology, 41, 41-48.

Piñeiro, A., \& Manzano, M. (2000). A lexical database for Spanishspeaking children. Behavior Research Methods, Instruments, \& Computers, 32, 616-628.

Rosch, E. (1975). Cognitive representations of semantic categories. Journal of Experimental Psychology: General, 104, 192-233.

Rosch, E., Mervis, C. B., Gray, W. D., Johnson, D. M., \& Boyes-
Braem, P. (1976). Basic objects in natural categories. Cognitive Psychology, 8, 382-439.

Schermelleh-Engel, K., Moosbrugger, H., \& Müller, H. (2003). Evaluating the fit of structural equation models: Tests of significance and descriptive goodness-of-fit measures. Methods of Psychological Research Online, 8, 23-74.

Severens, E., Van Lommel, S., Ratinckx, E., \& Hartsuiker, R. J. (2005). Timed picture naming norms for 590 pictures in Dutch. Acta Psychologica, 119, 159-187.

Sirois, M., Kremin, H., \& Cohen, H. (2006). Picture-naming norms for Canadian French: Name agreement, familiarity, visual complexity, and age of acquisition. Behavior Research Methods, 38, 300-306.

SNOdGRass, J. G., \& Yuditsky, T. (1996). Naming times for the Snodgrass and Vanderwart pictures. Behavior Research Methods, Instruments, \& Computers, 28, 516-536.

Stadthagen-Gonzalez, H., \& Davis, C. J. (2006). The Bristol norms for age of acquisition, imageability, and familiarity. Behavior Research Methods, 38, 598-605.

Székely, A., D’ Amico, S., Devescovi, A., Federmeier, K., Herron, D. IYER, G., ET AL. (2003). Timed picture naming: Extended norms and validation against previous studies. Behavior Research Methods, Instruments, \& Computers, 35, 621-633.

Wright, S. (1934). The method of path coefficients. Annals of Mathematical Statistics, 5, 161-215.

\section{SUPPLEMENTAL MATERIALS}

The word norms discussed in this article may be downloaded from http://brm.psychonomic-journals.org/content/supplemental.

(Manuscript received April 22, 2009; revision accepted for publication August 2, 2009.) 